\title{
Catalytic Cracking and Heat Sink Capacity of Aviation Kerosene Under Supercritical Conditions
}

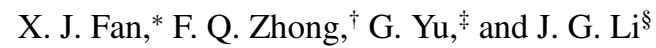 \\ Chinese Academy of Sciences, 100190 Beijing, People's Republic of China \\ and \\ C. J. Sung $\mathbb{1}$ \\ Case Western Reserve University, Cleveland, Ohio 44106
}

DOI: $\underline{10.2514 / 1.41966}$

\begin{abstract}
Catalytic cracking of China no. 3 aviation kerosene using a zeolite catalyst was investigated under supercritical conditions. A three-stage heating/cracking system was specially designed to be capable of heating $0.8 \mathrm{~kg}$ kerosene to a temperature of $1050 \mathrm{~K}$ and pressure of $7.0 \mathrm{MPa}$ with maximum mass flow rate of $80 \mathrm{~g} / \mathrm{s}$. Sonic nozzles of different diameters were used to calibrate and monitor the mass flow rate of the cracked fuel mixture. With proper experiment arrangements, the mass flow rate per unit throat area of the cracked fuel mixture was found to well correlate with the extent of fuel conversion. The gaseous products obtained from fuel cracking under different conditions were also analyzed using gas chromatography. Composition analysis showed that the average molecular weight of the resulting gaseous products and the fuel mass conversion percentage were a strong function of the fuel temperature and were only slightly affected by the fuel pressure. The fuel conversion was also shown to depend on the fuel residence time in the reactor, as expected. Furthermore, the heat sink levels due to sensible heating and endothermic cracking were determined and compared at varying test conditions. It was found that at a fuel temperature of $\sim 1050 \mathrm{~K}$, the total heat sink reached $\sim 3.4 \mathrm{MJ} / \mathrm{kg}$, in which chemical heat sink accounted for $\sim 1.5 \mathrm{MJ} / \mathrm{kg}$.
\end{abstract}

\section{Introduction}

$\mathbf{S}$ CRAMJEToperation at hypersonic speeds places severe cooling requirements on the engine structure. To limit the weight of the cooling system, regenerative cooling using onboard fuel as the primary coolant is considered to be the most effective way for thermal management. The fuel state before entering the combustor varies with different operation conditions. In the early (low-speed) stage for a liquid-hydrocarbon-fueled scramjet, because the amount of heat absorbed by the fuel is minimal, the hydrocarbon fuel would remain in the liquid state. As the flight speed increases, the fuel temperature may exceed its thermodynamic critical temperature, and the fuel can become supercritical when the fuel pressure is also supercritical. Moreover, when the fuel temperature is sufficiently high, fuel pyrolysis can occur as well. In these processes, the sensible heat of hydrocarbon fuel can meet the cooling requirements up to Mach 5-6, whereas for higher Mach numbers, additional cooling can be obtained by increasing the heat sink capacity of hydrocarbon fuel through endothermic reactions [1-7]. Among various endothermic reactions, the thermal cracking of hydrocarbons is the simplest type for practical applications. Unfortunately, the actual chemical heat sink from thermal cracking of hydrocarbon fuel is far behind the cooling demands, due to the large amount of methane formed at high temperatures [8-10]. A catalyst could be used to selectively enhance the rate of certain endothermic reactions and reduce the methane

Presented as Paper 5130 at the 44th AIAA/ASME/SAE/ASEE Joint Propulsion Conference and Exhibit, Hartford, CT, 21-23 July 2008; received 3 November 2008; revision received 25 July 2009; accepted for publication 8 August 2009. Copyright $\odot 2009$ by the American Institute of Aeronautics and Astronautics, Inc. All rights reserved. Copies of this paper may be made for personal or internal use, on condition that the copier pay the $\$ 10.00$ per-copy fee to the Copyright Clearance Center, Inc., 222 Rosewood Drive, Danvers, MA 01923; include the code 0748-4658/09 and \$10.00 in correspondence with the CCC.

*Professor, Institute of Mechanics, 15 Zhongguancun Road, Haidian District, xfan@imech.ac.cn; Member AIAA (Corresponding Author).

${ }^{\dagger}$ Associate Professor, Institute of Mechanics; fzhong @imech.ac.cn.

Professor, Institute of Mechanics; yugong@imech.ac.cn. Member AIAA.

\$Professor, Institute of Mechanics; jgli129@imech.ac.cn. Member AIAA.

TProfessor, Department of Mechanical and Aerospace Engineering; cjs15@case.edu. Associate Fellow AIAA. formation. For example, dehydrogenation of methylcyclohexane into toluene and hydrogen using platinum catalysts can provide a chemical heat sink of $2.2 \mathrm{MJ} / \mathrm{kg}$ [1]. Cracking tests of JP-7 fuel using zeolite coating by Unit Technologies Research Center recorded a total heat sink of $4.0 \mathrm{MJ} / \mathrm{kg}$ at $1100 \mathrm{~K}$ [5] .

Because a wide range of fuel states and composition variations can exist in the fuel injection system, it is imperative to understand how the fuel is decomposed and how the changes in fuel properties affect the injection behavior and the subsequent combustion processes in a supersonic combustor. In particular, in the supercritical and cracking region, the fuel properties change dramatically, which leads to some difficulties in flow rate control. To further our understanding of the preceding important issues, we experimentally investigated and systematically compared the performance of model supersonic combustors with the injection of liquid kerosene [11-13] and vaporized/ supercritical kerosene [14]. The fuel cracking characteristics and the associated effects on supersonic combustion were also studied through a series of experiments using a specially designed kerosene heating and delivery system, which can operate to a temperature of $1050 \mathrm{~K}$ and pressure of $6.0 \mathrm{MPa}$ with minimal/negligible fuel coking [15-17]. Experimental results [14,15] demonstrated that the overall burning intensity as well as combustion efficiency improved with supercritical/cracked kerosene injection and generally increased with increasing fuel temperature. It was also shown that the use of sonic nozzles is adequate for the control and flow rate measurement of supercritical and/or cracked kerosene [14-16].

The current research focuses on catalytic fuel reforming and is a continuing work to determine the endothermic properties of aviation kerosene under conditions relevant to practical scramjet applications. China no. 3 aviation kerosene, which is similar to JP-8, was selected as the test fuel. Stainless-steel plates coated with HZSM-5 zeolite using ceramic binder were used to construct a catalytic reactor. A three-stage kerosene heating/cracking system using multiple-layered parallel plates as the key heat exchanger was designed and established, which can operate at temperature up to $1050 \mathrm{~K}$ and pressure up to $7.0 \mathrm{MPa}$. In this experimental investigation, the extent of fuel conversion, the composition of gaseous products, the resulting heat sink, and the mass flow rate of cracked fuel mixture were measured and compared at varying conditions. In addition, the effects of pressure, temperature, and flow rate on fuel cracking were examined 
and discussed. In the following description and demonstration of the present experimental facility, calibration and measurement of cracked fuel flow rate using sonic nozzles, composition analysis of gaseous products using gas chromatography, and key experimental results will be sequentially presented.

\section{Experimental Apparatus}

\section{A. Kerosene Heating and Cracking System}

Because the fuel coking is proportional to the fuel residence time at high temperatures, it can be minimized by changing the fuel heating history. To limit the fuel residence time at high temperatures, a threestage fuel-heating/catalytic-cracking system (as shown in Fig. 1) was developed for the present experiments. Before each experiment, liquid kerosene in a storage cylinder was pumped at supercritical pressure into the first-stage heater by a piston. The first-stage heater was a storage type that preheated kerosene of $0.8 \mathrm{~kg}$ up to $570 \mathrm{~K}$ in 10-15 min without severe coking deposits. When kerosene in the first-stage heater reached the desired temperature at a given pressure, kerosene was pressed by high-pressure nitrogen into the secondstage heater, and was then further heated up to $770 \mathrm{~K}$. The residence time of kerosene in the second-stage heater was also kept short, typically less than $2 \mathrm{~s}$, thereby minimizing the extent of fuel coking. The third-stage heater, connected directly to the second-stage heater, was capable of rapidly heating kerosene up to $1050 \mathrm{~K}$. For the present investigation, the fuel reforming reactor, as detailed later, was situated inside this third-stage heater. When kerosene was prepared to a desired temperature via the first- and second-stage heaters and the fuel reforming reactor was preheated to a specific temperature by the third-stage heater, the third-stage heater was powered off and kerosene flowed through the reactor for conducting heat exchange characterization experiments. The choice of this storage heater concept was to reduce the amount of total power required as compared with the cases of using electrically heated tubes in a number of direct-connect facilities. Two pneumatic valves (Swagelok, model no. SS10UM) were installed at the exits of the first- and third-stage heaters, as shown in Fig. 1, and were employed to turn on/off the fuel flow. Typically, the fuel residence time in the fuel reforming reactor was around $1-2 \mathrm{~s}$.

The first- and second-stage heaters were nearly identical in construction and each was composed of a 20-m-long stainless-steel tube of $20 \mathrm{~mm}$ outer diameter and $1.5 \mathrm{~mm}$ wall thickness, wound into a cylinder shape of $30 \mathrm{~cm}$ diameter. To reach a uniform temperature distribution along the heater, three independently controlled electrical heating rugs were wrapped outside the cylinder. The heating rugs were composed of high-temperature infrared ceramic tiles woven by resistance wires, and each rug had a maximum power of $6 \mathrm{~kW}$. Two groups of K-type thermocouples, TC11-TC13 and TC21-TC25 in Fig. 1, were installed on the surface of or inserted into the heater tubes and were used to monitor and achieve the feedback control of fuel temperature distribution along the two heaters.

Figure 2 shows a schematic of the third-stage heater/reactor system. This fuel reactor was installed inside a high-pressure cylindrical container with an outside diameter of $82 \mathrm{~mm}$, which was placed inside an oven, as shown in Fig. 2. The oven was made of a stainless-steel pipe of $220 \mathrm{~mm}$ inner diameter and $4 \mathrm{~mm}$ wall thickness with a total length of $1.25 \mathrm{~m}$. To reach a uniform temperature distribution along the oven hull, four independently controlled electrical heating rugs were wrapped outside the pipe. The oven along with the fuel reactor can be heated up to $1050 \mathrm{~K}$ within $30 \mathrm{~min}$.

To increase the contact surface area between fuel and reactor/heat exchanger, the heat exchanger was made of parallel stainless-steel plates of $0.7 \mathrm{~m}$ length and $1.5 \mathrm{~mm}$ thickness spaced evenly with a $0.5 \mathrm{~mm}$ gap. The total weight of the heat exchangers was approximately $21.5 \mathrm{~kg}$. Table 1 lists the geometric parameters of the heat exchanger system. The overall surface/volume ratio was $\sim 3.2 \mathrm{~mm}^{-1}$, which is equivalent to the surface/volume ratio of a tube of $1.2 \mathrm{~mm}$ diameter.

The parallel stainless-steel plates were coated with HZSM-5 zeolite catalyst using ceramic binder. To strengthen the binding of catalyst coating on the stainless-steel plates, the surfaces of the plates were sandblasted before coating. The overall Si/Al ratio in HZSM-5 was approximately 50. The typical particle size of the HZSM-5 catalyst was less than $5 \mu \mathrm{m}$ and the average pore diameter was $5 \AA$, and the thickness of the coating was approximately $20-30 \mu \mathrm{m}$. Before the catalytic reactor could be used for experiments, the system was heated up slowly to the working temperature to evaporate the absorbed water and solidify the zeolite framework. The heating rate was $1-3 \mathrm{~K} / \mathrm{min}$ and the whole process took approximately $10 \mathrm{~h}$.

Two groups of K-type thermocouples with diameters of $0.3 \mathrm{~mm}$ (Omega, model no. KMQSS-040G), TW1-TW8 and TF1-TF8 in Fig. 2, were welded on the surface of the plates or inserted into the reactor and were used to monitor the plate and fuel temperature distributions along this reactor/heat exchanger system. The error in

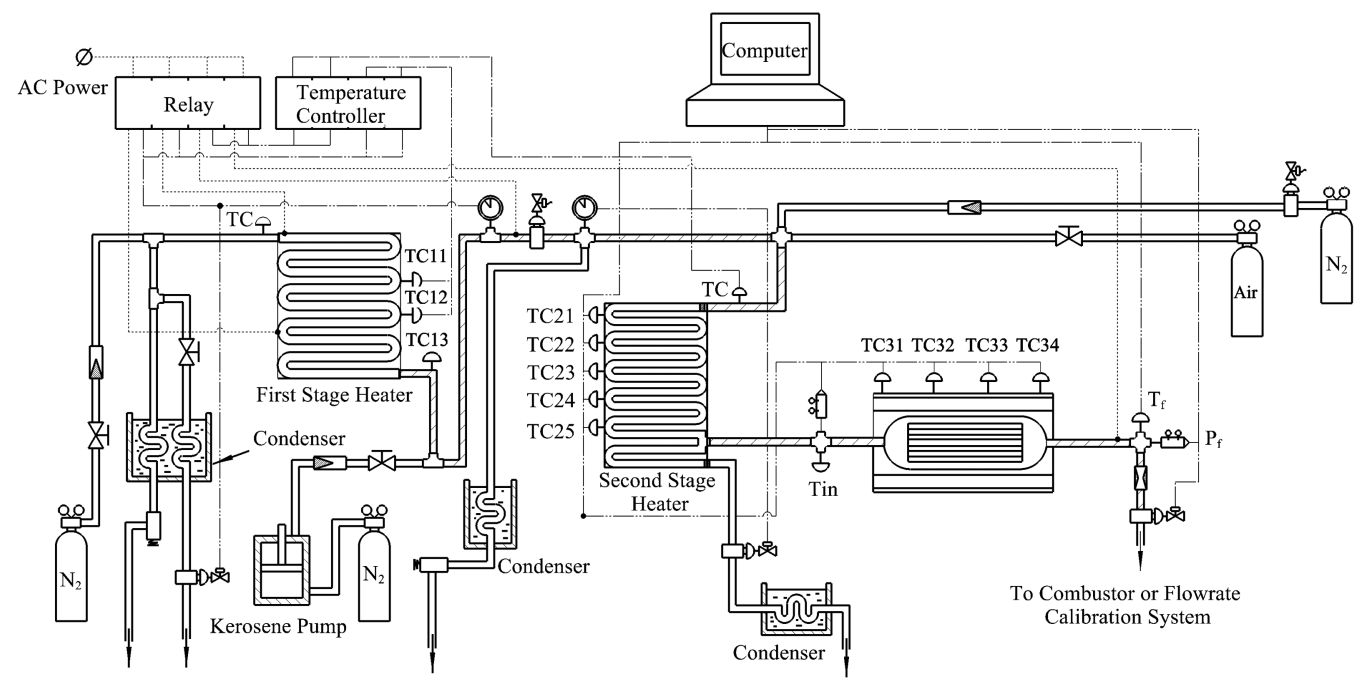
(1) Pressure Gauge
安 Solenoid Valve
Pressure Sensor $\square$ - Flowrate Meter
웅 Regulator
ठ̊ Pneumatical Valve
凶 Manual Valve
-1 Relief Valve
- - One Way Valve
个 Thermocouple
$\square$ Stainless Steel Tube
Data Line
Power Line

Fig. 1 Schematic of kerosene heating/cracking system. 


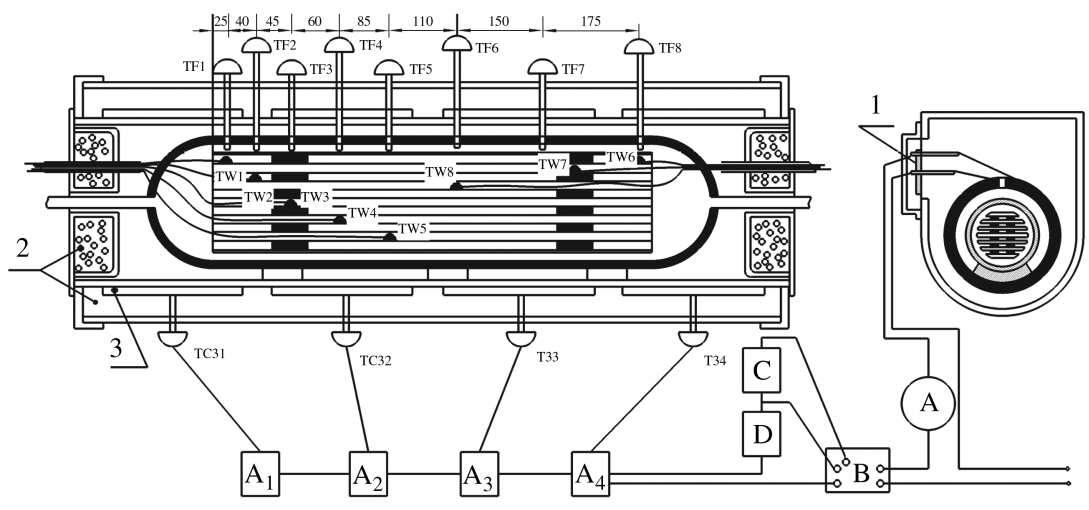

1:Power Connection Board
TF1 - TF8: Fuel Temperature Sensors
TW1 - TW8: Wall Temperature Sensors

2:Insulation material $\quad 3:$ Heating Rugs

TC31-TF34:Temperature Controller Thermocouple

A1-A4: Temperature Controller
A: AC Power
B:SCR
C:DC Power
D: Voltage Ragulator

Fig. 2 Schematic of the third-stage heater/reactor system. For clarity, not all of the flat plates are sketched. All dimensions are in millimeters.

the temperature measurement was within $\pm 3 \mathrm{~K}$. Additional measurements also showed that the radial variation of plate temperature at given axial locations is less than $10 \mathrm{~K}$.

Because the catalyst could be deactivated due to coke deposits after several runs, special caution was exercised. It was found that the color of the catalyst coating became light brown after several runs, which indicated that the coke formation during the experiments was not severe. However, because the thermal isolation of the cracking system was so good, it took more than $10 \mathrm{~h}$ to cool down to the room temperature at the end of day. During this long cooling duration, the residual fuel inside the tank could form coke. To avoid this problem, a small amount of airflow was introduced into the reactor at the end of experiments to slowly consume the fuel residuals.

\section{B. Fuel Collection and Flow Rate Calibration System}

Figure 3 shows a schematic of the kerosene collection and flow rate calibration system. The mass flow rate of cracked kerosene was measured using a sonic nozzle installed at the exit of the third-stage heater. After passing through the sonic nozzle, the cracked fuel mixture was cooled down to room temperature using an air-conditioner condenser circulated with cold water. The liquid products and carbon deposits (if present) were collected directly after cooling and the gaseous products were collected using a container immersed in a water pool, and the mixture volume was measured by the volume of water displaced.

The composition of gaseous product mixture was analyzed using a gas chromatograph, and its average molecular weight and density were determined. The gas density was also measured directly by the measurements of the weight and volume of a gas sample. The mass flow rate was determined from the total mass of collected liquid and gaseous products divided by the time duration of fuel discharging, which was precisely controlled by the pneumatic valves through a computer. Note that the mass flow rate is, in general, a function of the fuel temperature upstream of the nozzle and the average molecular weight of the cracked kerosene and that the average molecular weight is a function of the fuel temperature at the exit of the reactor. As such, the tube used to connect the reactor exit and the upstream sonic

Table 1 Geometrical parameters of the heat exchanger system

\begin{tabular}{lc}
\hline \hline Parameters & Values \\
\hline Passage height & $0.5 \mathrm{~mm}$ \\
Total length & $700 \mathrm{~mm}$ \\
Contact surface & $3.1 \mathrm{~m}^{2}$ \\
Passage volume & $0.98 \mathrm{dm}^{3}$ \\
Surface/volume ratio & $3.2 \mathrm{~mm}^{-1}$ \\
\hline \hline
\end{tabular}

nozzle was wrapped with heating tapes so that the reference temperature was kept almost the same and the fuel mass flow rate could be calibrated using a single temperature. Because of the large variation of kerosene density in the temperature range of 570-1050 K, two different throat diameters of 1.62 and $2.55 \mathrm{~mm}$ were used to meter the desired mass flow rate. A discharging valve (Swagelok, model no. SS10UM) was also installed upstream of the sonic nozzle to discharge some cracked fuel during pressure buildup before the fuel mixture was actually collected and analyzed so that the fuel cracking process during sampling occurred at almost constant pressure.

\section{Results and Discussion}

\section{A. Characteristics of the Fuel Reactor}

A stable temperature and pressure at the exit of the fuel reactor is essential for the future supersonic combustion experiments. To achieve this, precise setting of the time sequence for the two valves used to control the fuel flow into and out of the reactor is required. Again, the third-stage heater was turned off before flowing fuel into the reactor. Figure $\underline{4}$ shows the typical time histories of the fuel pressure measured at the inlet and outlet of the reactor. The fuel was pressed into the second-stage heater and the reactor at a reference time of $t \approx 1 \mathrm{~s}$. At this time both the fuel discharging and collection valves in Fig. 3 were closed. The pressure inside the reactor increased quickly to a desired value at $t \approx 4 \mathrm{~s}$, at which the discharging valve was opened. After about $4 \mathrm{~s}$ fuel discharging, at $t \approx 8 \mathrm{~s}$ the fuel collection valve was opened and the discharging valve was closed. It can be seen from Fig. $\underline{4}$ that both inlet and outlet fuel pressures were stabilized during the sampling process. The two level-off pressures were also seen to be very close. This small pressure drop indicates that the flow resistance within the reactor was minimal.

Figure $\underline{5}$ shows the typical time histories of the plate wall temperatures (TW1-TW8 in Fig. 2) inside the fuel reactor. It is seen that the temperature distribution along the reactor was fairly uniform at the beginning, with temperature variation of TW1-TW8 being less than $25 \mathrm{~K}$. When kerosene was introduced into the reactor, the temperature decreased quickly during the first $4 \mathrm{~s}$ but its reduction rate became much smaller after $t \approx 8 \mathrm{~s}$.

Figure $\underline{6}$ further compares the distributions of total plate wall temperature reduction in the period of $t=8-12 \mathrm{~s}$ along the reactor for three different final fuel exit temperatures of 815,854 , and $920 \mathrm{~K}$. In calculating such a total temperature reduction for each plate thermocouple, linear regression was employed to fit the raw data between $t=8$ and $12 \mathrm{~s}$ to reduce the error. For the case of $815 \mathrm{~K}$, the total wall temperature reduction decreases monotonically along the reactor. Hence, sensible heat dominates at this relatively lower-fueltemperature condition. As fuel temperature is increased, the cases of 854 and $920 \mathrm{~K}$ in Fig. 6 exhibit nonmonotonic response, indicating the occurrence of thermal and/or catalytic-cracking reactions. 


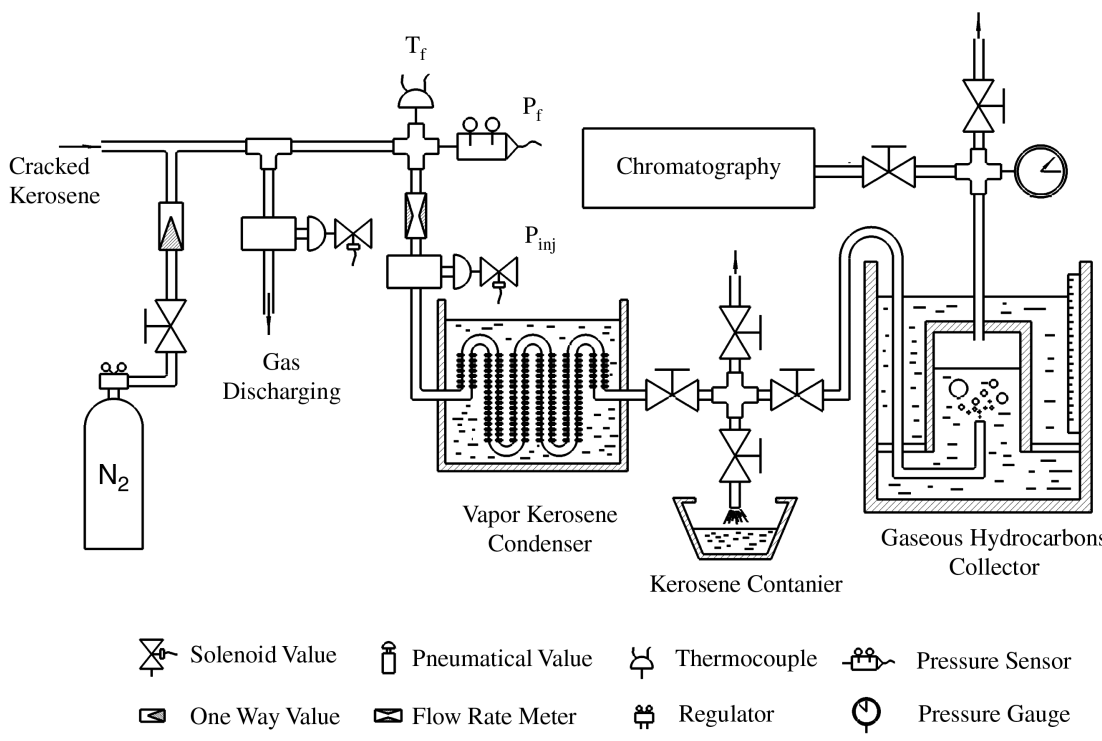

Fig. 3 Schematic of cracked fuel mixture collection and flow rate calibration system.

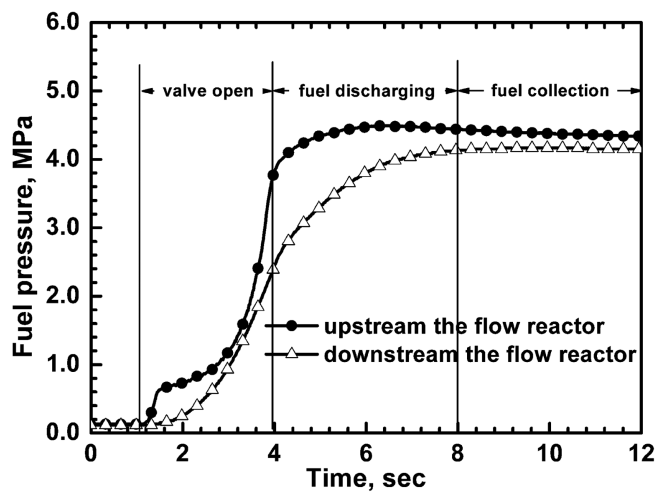

Fig. 4 Time histories of fuel pressures measured at the inlet and the exit of fuel reactor.

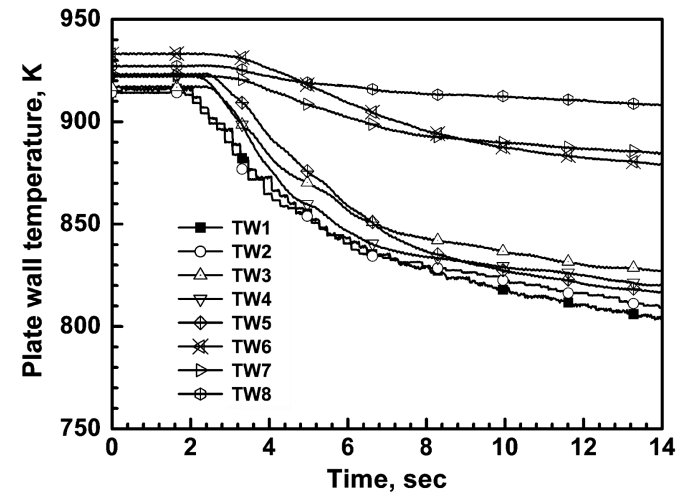

Fig. 5 Time histories of the plate wall temperatures along the fuel reactor.

\section{B. Catalytic Cracking of China No. 3 Kerosene}

China no. 3 aviation kerosene was employed in this study. On the volume basis, it is approximately composed of $92.5 \%$ saturated hydrocarbons, $0.5 \%$ unsaturated hydrocarbons, and $7 \%$ aromatic hydrocarbons. Its mass composition distribution by carbon number from chromatograph is shown in Fig. 7. The overall chemical formula of this kerosene is approximately $\mathrm{C}_{11} \mathrm{H}_{22}$.

The major gaseous products obtained from catalytic cracking were hydrogen, methane, ethane, propane, ethylene, and propylene. Figure 8 compares the composition variations of the gaseous

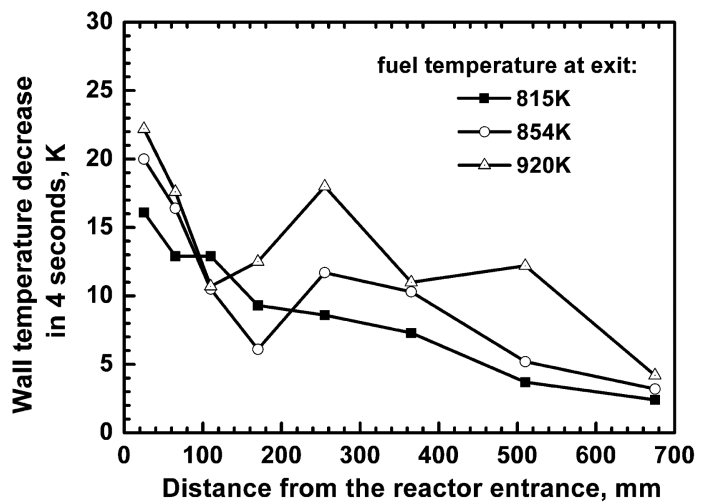

Fig. 6 Comparison of total plate wall temperature reductions from $t=8 \mathrm{~s}$ to $t=12 \mathrm{sec}$ along the reactor for the cases with three different final fuel temperatures at the exit.

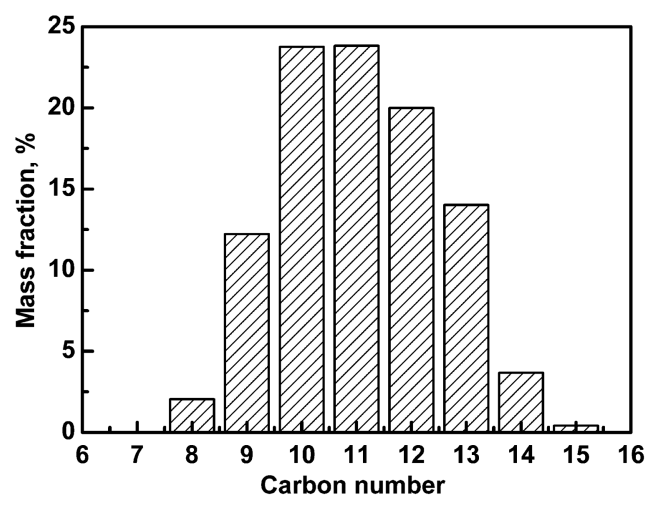

Fig. 7 Composition distribution of China no. 3 kerosene.

products at six different exit fuel temperatures, ranging from 813 to $942 \mathrm{~K}$. The pressure was kept constant at a value of approximately 4.1 MPa. It is seen from Fig. $\underline{8}$ that increasing fuel temperature generally led to larger conversion to methane, ethane, and hydrogen, but smaller conversion to alkenes. Estimated composition data for catalytically cracking JP-8+100 at $4.1 \mathrm{MPa}$ and $940 \mathrm{~K}$ taken from [5] are also plotted in Fig. 8 for comparison, showing a similar species distribution as the present measurements. The increase in methane formation at high temperatures is expected to reduce the endothermicity of the fuel, which is commonly represented by the so-called 


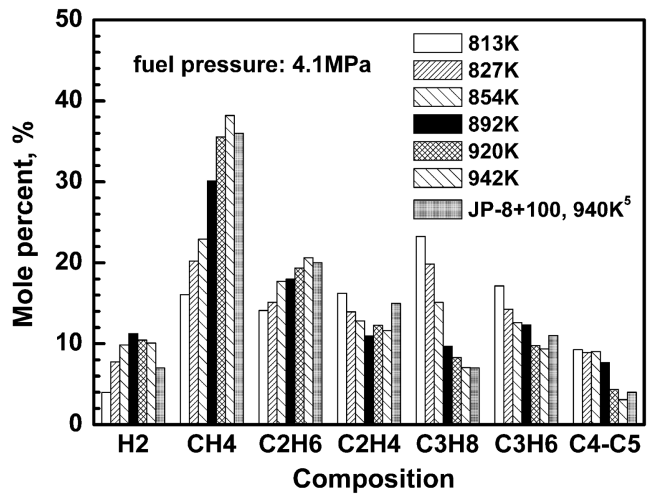

Fig. 8 Comparison of gaseous product compositions at varying fuel temperatures. Fuel pressure was kept constant at 4.1 MPa. Sonic nozzle diameter used in the current experiments was $2.55 \mathrm{~mm}$.

olefin/paraffin ratio [9]. A higher olefin/paraffin ratio indicates a better endothermicity. The olefin/paraffin mole ratios, defined by ethylene plus propylene with methane plus ethane plus propane using the data of Fig. $\underline{8}$, are further listed in Table 2 , demonstrating that the olefin/paraffin ratio from catalytic cracking decreased as the fuel temperature is increased. It is seen from Table 2 that the olefin/ paraffin ratio for JP-8+100 at 4.1 MPa and $940 \mathrm{~K}$ from [ㄷ] is slightly higher than the present data.

Figure 9 further compares the composition variations of the gaseous products at four different fuel pressures, ranging from 3.2 to 5.1 MPa. The exit fuel temperature was kept nearly constant in the range of 890-900 K. Figure 9 shows that increasing fuel pressure generally led to larger conversion to methane, but a smaller conversion to hydrogen. Moreover, the influence of pressure on the formations of other species was relatively smaller, which suggests that the associated catalytic reactions were less sensitive to pressure for the conditions investigated.

Note that a lower endothermicity does not mean a lower heat sink available. The heat sink is also dependent on the extent of fuel conversion. Figure 10 plots the mass percentage of kerosene converted to gaseous products as a function of fuel temperature for two different sonic nozzle throat diameters of 1.62 and $2.55 \mathrm{~mm}$. It shows that for a given sonic nozzle the fuel conversion increased with increasing fuel temperature. The mass conversion is also seen to level off beyond $1000 \mathrm{~K}$, which could be because the temperature may not be high enough to pyrolyze some heavy compounds such as aromatics and other tarlike intermediates from cracking. Even though the fuel pressure varied from 2.7-5.2 MPa in Fig. 10, the measurements showed only a slight dependence of fuel conversion on fuel pressure. Figure 10 also demonstrates that at the same fuel temperature, the larger the sonic nozzle diameter, the less fuel conversion. This is because a larger throat diameter corresponds to a larger fuel mass flow rate, thereby resulting in a shorter residence time. Figure 11 further shows the averaged molecular weight of the gaseous products at different fuel temperatures. The average molecular weight was found to decrease nearly linearly with increasing fuel temperature, corresponding to the increase in methane and hydrogen formation demonstrated in Fig. $\underline{8}$.

\section{Measurements of Fuel Mass Flow Rate}

The measured total mass flow rates of cracked fuel mixture $Q$ per unit throat area $A^{*}$ at varying fuel temperatures are compared in Fig. 12 for the two different sonic nozzles used in the present experiments. All data were normalized with a reference pressure of 3.5 $\mathrm{MPa}$, and hence $3.5 Q /\left(P A^{*}\right)$ is plotted in Fig. 12, in which

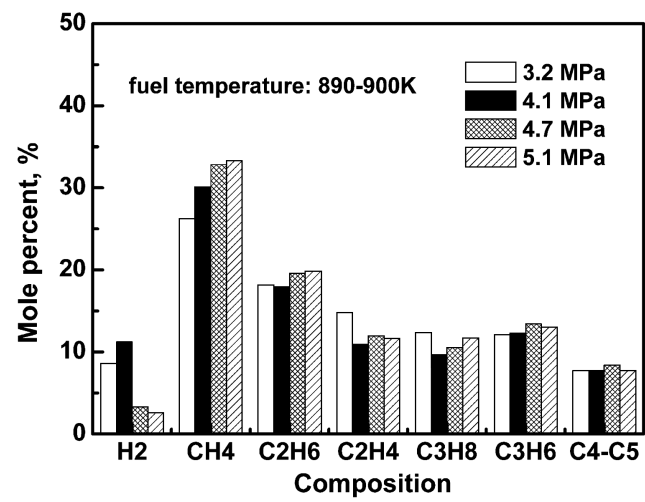

Fig. 9 Comparison of gaseous product compositions at varying fuel pressures. Fuel temperature was kept nearly constant in the range of 890-900 K. Sonic nozzle diameter used in these experiments was $2.55 \mathrm{~mm}$.

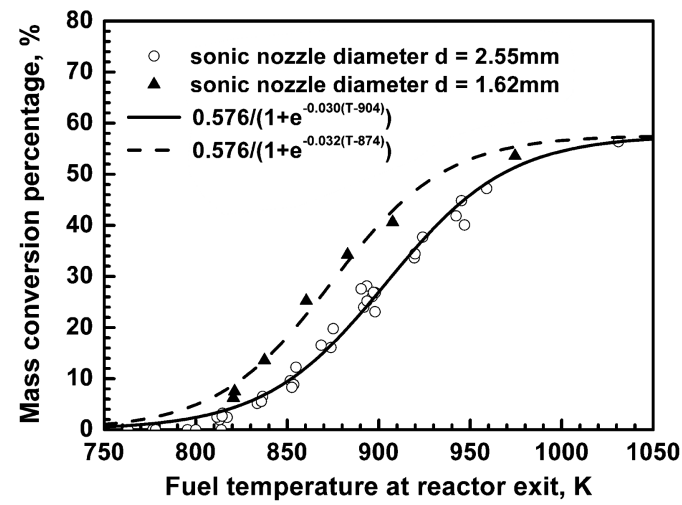

Fig. 10 Mass percentage of kerosene conversion to gaseous products as a function of fuel temperature for two different sonic nozzles (i.e. different mass flow rates). Fuel pressure ranged from 2.7 to 5.2 MPa.

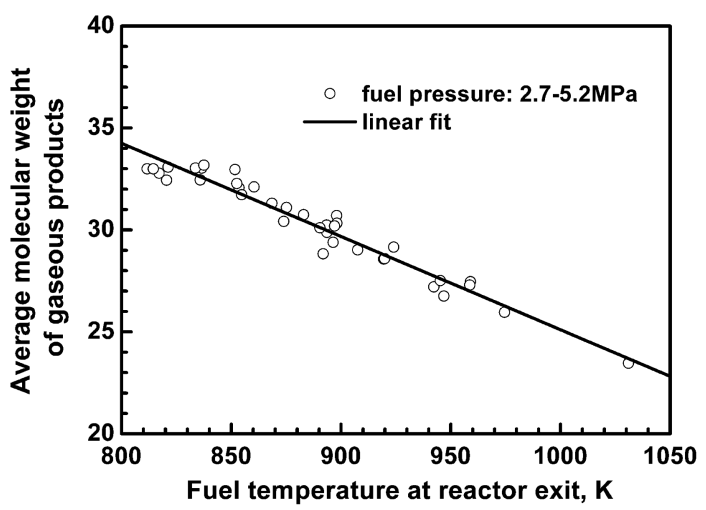

Fig. 11 Averaged molecular weight of gaseous products as a function of fuel temperature.

pressure $P$ is in units of megapascals. For comparison, calculations using the model of extended corresponding states (ECS) [18] for a kerosene surrogate developed in our early study [15] are also plotted in Fig. 12. Without considering fuel cracking, the computed results agreed well with the experimental data up to a temperature of approximately $800 \mathrm{~K}$, above which fuel cracking is expected to

Table 2 Variation of olefin/paraffin mole ratio (ethylene plus propylene with methane plus ethane plus propane) with fuel temperature at fuel pressure of $4.1 \mathrm{MPa}$ (cf. Figure 8 )

\begin{tabular}{lccccccc}
\hline \hline Fuel temperature, K & 813 & 827 & 854 & 892 & 920 & 942 & JP-8+100 at 940 K [5] \\
Olefin/paraffin ratio & 0.62 & 0.51 & 0.46 & 0.40 & 0.35 & 0.32 & 0.41 \\
\hline \hline
\end{tabular}




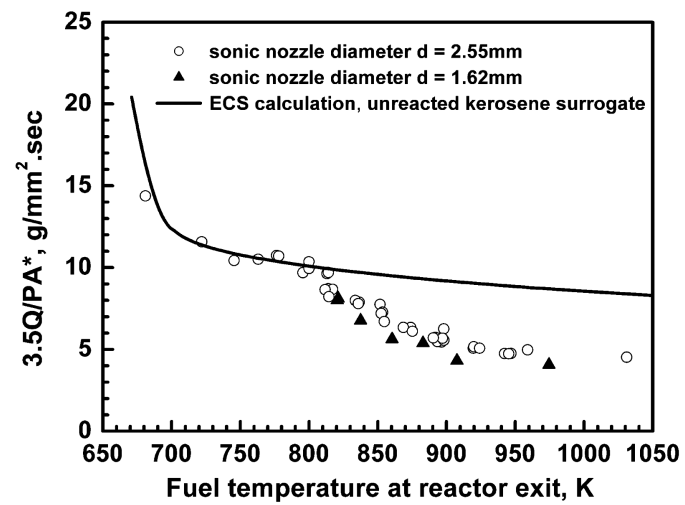

Fig. 12 Mass flow rates per unit throat area at varying fuel temperatures for two different sonic nozzles. All data were normalized with a reference pressure of 3.5 MPa. Calculations using an unreacted kerosene surrogate are also included for comparison.

occur. It is also seen from Fig. 12 that for fuel temperatures greater than $800 \mathrm{~K}$, some nozzle diameter dependence of the measured data was noted. Such a deviation can be explained by the differences in fuel conversion percentage shown in Fig. 10. By replotting the normalized mass flow rates per unit throat area in terms of fuel mass conversion percentage, Fig. 13 shows that all data now collapse into one curve, indicating a direct correlation of $Q / P A^{*}$ with fuel mass conversion percentage.

\section{Heat Sink Measurements}

The heat sink from fuel cracking can be determined by the heat exchange $\Delta Q$ of the stainless-steel reactor within a certain time interval $\Delta t$, which is from $t=8$ to $12 \mathrm{~s}$, shown in Fig. 4 . Based on the total plate temperature drops $\Delta T(x)$ when fuel flows through the reactor, $\Delta Q$ is determined by

$$
\Delta Q=\rho_{s} C_{p, s} A_{s} \int_{0}^{L} \Delta T(x) \mathrm{d} x
$$

where $\rho_{s}$ is the density of stainless steel, $C_{p, s}$ is the heat capacity of stainless steel, $A_{s}$ is the cross-sectional area occupied by the stainless-steel plates, $L$ is the reactor length, and $x$ is the distance from the reactor entrance. The specific sensible heat $h_{\text {sensible }}$, related to the fuel temperature changes from the inlet to the exit of the reactor, can be calculated by

$$
h_{\text {sensible }}=h_{f}\left(T_{e}\right)-h_{f}\left(T_{i}\right)
$$

where $T_{i}$ and $T_{e}$ are, respectively, the inlet and exit temperatures and $h_{f}$ is the fuel enthalpy calculated using the ECS model as in [15].

Because of the relatively slow rate change in fuel temperature, the error by neglecting the unsteadiness in fuel enthalpy was estimated to

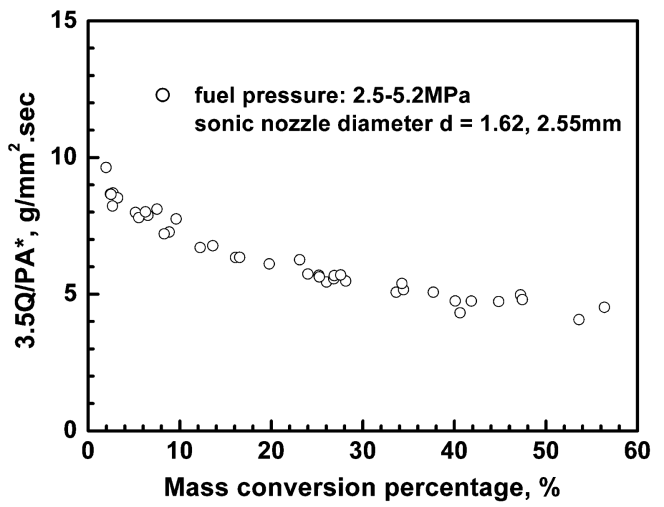

Fig. 13 Correlation of the mass flow rates per unit throat area of Fig. 12 with mass conversion percentage.

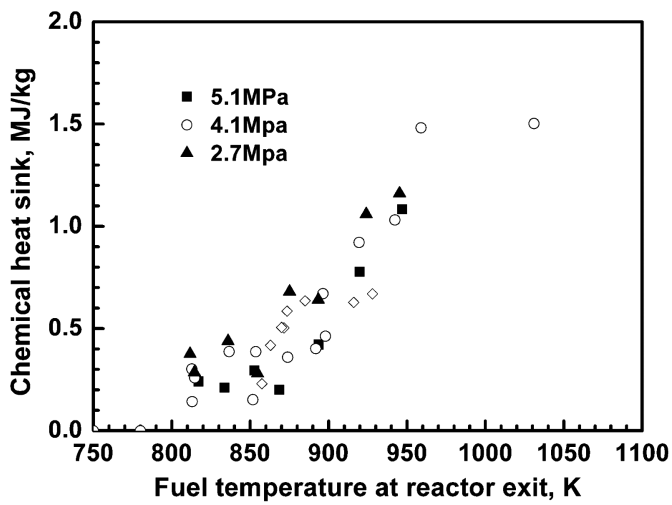

Fig. 14 Chemical heat sink values of China no. 3 kerosene at varying fuel temperatures. Sonic nozzle diameter used in these experiments was $2.55 \mathrm{~mm}$.

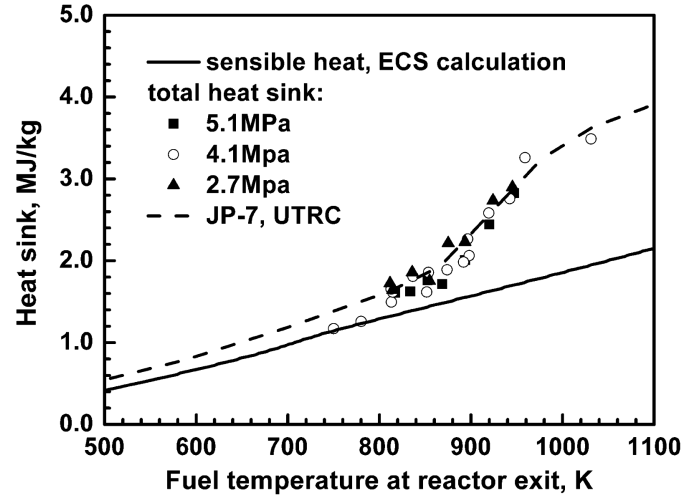

Fig. 15 Total heat sink values of China no. 3 kerosene at varying fuel temperatures. Sonic nozzle diameter used in the current experiments was 2.55 mm. (UTRC denotes the United Technologies Research Center.)

be $\sim 5 \%$. Thus, the heat sink available from fuel cracking can be determined by

$$
h_{\text {endothermic }}=\left(\Delta Q / \Delta m_{f}-h_{\text {sensible }}\right)
$$

where $\Delta m_{f}$ is the fuel mass collected during $\Delta t$

Figure 14 shows the chemical heat sink $h_{\text {endothermic }}$ of China no. 3 kerosene as a function of fuel temperature at pressures of 2.7, 4.1, and 5.2 MPa. A sonic nozzle of $2.55 \mathrm{~mm}$ in diameter was used in the flow rate control. The fuel mass flow rate tested ranged from 20 to $70 \mathrm{~g} / \mathrm{s}$. It is seen from Fig. 14 that the heat sink level due to endothermic reactions can reach $\sim 1.5 \mathrm{MJ} / \mathrm{kg}$ at temperature of $\sim 1050 \mathrm{~K}$. Despite a relatively larger scatter in the deduced $h_{\text {endothermic }}$, no apparent pressure dependence was observed. The corresponding total heat sink is further plotted in Fig. 15. The sensible heat sinks shown in Fig. 15 were calculated using the National Institute of Standards and Technology SUPERTRAPP [18] and the unreacted kerosene surrogate used in [15]. Figure 15 demonstrates that the total heat sink reached approximately $3.4 \overline{\mathrm{M}} / \mathrm{kg}$ at a temperature of around $1050 \mathrm{~K}$. In general, the present data are consistent with the results reported in [5] using JP-7. We further note that the equivalent liquid hourly space velocity (LHSV), defined as the volumetric flow rate of the fuel in its liquid state divided by the volume of the reactor [5], for the present reactor varied from 100 to $350 \mathrm{~h}^{-1}$ in this study, which was about one order of magnitude smaller than the LHSV used in [5] (500-3000 $\left.\mathrm{h}^{-1}\right)$. A higher heat sink corresponding to a higher fuel conversion would be expected at the lower space velocity [5], which, however, could not be seen in Fig. 15 when comparing the current data with the results of [5] . This may be due to a different fuel and catalyst used in the experiments 


\section{Conclusions}

A novel three-stage kerosene heating/cracking system was designed and tested for the catalytic cracking of aviation kerosene. The first-stage storage-type heater can preheat $0.8 \mathrm{~kg}$ kerosene to a temperature of $570 \mathrm{~K}$ and pressure of $7.0 \mathrm{MPa}$, whereas the secondstage continuous-flow-type heater can heat kerosene flow further, up to $770 \mathrm{~K}$. The third-stage heater had a structure of multilayered parallel stainless-steel plates to maximize the contact surface area and also served as a fuel reactor. These stainless-steel plates were coated with a zeolite catalyst using ceramic binder for effecting catalytic reactions. The fuel can be heated up to $1050 \mathrm{~K}$ when passing through this reactor at a flow rate up to $80 \mathrm{~g} / \mathrm{s}$, with residence time being around 1-2 s. In addition, sonic nozzles were used to measure the mass flow rate of the cracked fuel mixture. It was demonstrated that as long as the fuel temperature was kept constant from the exit of the reactor to the sonic nozzle, the mass flow rate per unit throat area of the cracked fuel could be correlated very well with the extent of fuel conversion.

Experimental results using China no. 3 kerosene showed that the total heat sink reached $\sim 3.4 \mathrm{MJ} / \mathrm{kg}$ at a fuel temperature of around $1050 \mathrm{~K}$ and the corresponding chemical heat sink due to endothermic reactions was $\sim 1.5 \mathrm{MJ} / \mathrm{kg}$. It was also found that both the average molecular weight of cracked gaseous products and the fuel mass conversion percentage were a strong function of fuel temperature but only slightly affected by the fuel pressure. Furthermore, the extent of fuel conversion was dependent on the fuel residence time in the reactor. The present results therefore provide insights into regenerative fuel cooling technologies and catalytic fuel cracking modeling.

\section{Acknowledgments}

Current research program at the Chinese Academy of Sciences was supported by the National Natural Science Foundation of China under contract no. 10672169. The authors would like to acknowledge X. W. Zhang of Tianjin University for the assistance in zeolite preparation and gas analyses. We also thank X. N. Lu, Y. Li, and X. S. Wei for their technical support.

\section{References}

[1] Lander, H., and Nixon, A. C., "Endothermic Fuels for Hypersonic Vehicles," Journal of Aircraft, Vol. 8, No. 4, 1971, pp. 200-207. doi: $10.2514 / 3.44255$

[2] Ianovsky, L. S., Sosounov, V. A., and Shikhman, Y. M., "Endothermic Fuels for Hypersonic Aviation," Fuels and Combustion Technology for Advanced Aircraft Engines, AGARD, CP-536, Neuilly-sur-Seine, France, 1993, pp. 44-1-44-8.

[3] Sobel, D. R., and Spadaccini, L. J., "Hydrocarbon Fuel Cooling Technologies for Advanced Propulsion," Journal of Engineering for Gas Turbines and Power, Vol. 119, No. 2, 1997, pp. 344-351. doi:10.1115/1.2815581

[4] Maurice, L., and Edwards, T., "Liquid Hydrocarbon Fuels for Hypersonic Propulsion," Scramjet Propulsion, edited by E. T. Curran, and S. N. B. Murthy, Progress in Astronautics and Aeronautics, Vol. 189, AIAA, Reston, VA, 2001, pp. 757-822.

[5] Huang, H., Spadaccini, L. J., and Sobel, D. R., "Fuel-Cooled Thermal Management for Advanced Aeroengines," Journal of Engineering for
Gas Turbines and Power, Vol. 126, No. 2, 2004, pp. 284-293. doi: $10.1115 / 1.1689361$

[6] Cooper, M., and Shepherd, J. E., "Experiments Studying Thermal Cracking, Catalytic Cracking, and Pre-Mixed Partial Oxidation of JP10," 39th Joint Propulsion Conference, AIAA Paper 2003-4687, Huntsville, AL, July 2003.

[7] Daniau, E., Falempin, F., Herbinet, O., and Marquaire, P. M., "Numerical Simulations and Experimental Results of Endothermic Fuel Reforming for Scramjet Cooling Application," 14th AIAA/AHI Space Planes and Hypersonic Systems and Technologies Conference, AIAA Paper 2006-7975, Canberra, Nov. 2006.

[8] Fabuss, B. M., Smith, J. O., and Satterfield, C. N., "Rapid Thermal Cracking of n-Hexadecane at Elevated Pressures," Industrial and Engineering Chemistry Process Design and Development, Vol. 1, No. 4, 1962, pp. 293-299. doi:10.1021/i260004a011

[9] Edwards, T., and Anderson, S. D., "Results of High Temperature JP-7 Cracking Assessment," AIAA Paper 93-0806, Jan. 1993.

[10] Edwards, T., "Cracking and Deposition Behavior of Supercritical Hydrocarbon Aviation Fuels," Combustion Science and Technology, Vol. 178, Nos. 1-3, 2006, pp. 307-334. doi:10.1080/00102200500294346

[11] Yu, G., Li, J. G., Zhang, X. Y., Chen, L. H., and Sung, C. J., "Investigation of Kerosene Combustion Characteristics with Pilot Hydrogen in Model Supersonic Combustors," Journal of Propulsion and Power, Vol. 17, No. 6, 2001, pp. 1263-1272. doi: $10.2514 / 2.5874$

[12] Yu, G., Li, J. G., Zhang, X. Y., Chen, L. H., and Sung, C. J., "Fuel Injection and Flame Stabilization in a Liquid Kerosene-Fueled Supersonic Combustor," Journal of Propulsion and Power, Vol. 19, No. 5, 2003, pp. 885-893. doi: $10.2514 / 2.6179$

[13] Yu, G., Li, J. G., Zhao, J. R., Yue, L. J., Chang, X. Y., and Sung, C. J., "An Experimental Study of Kerosene Combustion in a Supersonic Model Combustor Using Effervescent Atomization," Proceedings of the Combustion Institute, Vol. 30, No. 2, 2005, pp. 2859-2866. doi:10.1016/j.proci.2004.07.050

[14] Fan, X. J., Yu, G., Li, J. G., Zhang, X. Y., and Sung, C. J., "Investigation of Vaporized Kerosene Injection and Combustion in a Supersonic Model Combustor," Journal of Propulsion and Power, Vol. 22, No. 1, 2006, pp. 103-110. doi: $10.2514 / 1.15427$

[15] Fan, X., Yu, G., Li, J. G., Lu, X. N., Zhang, X. Y., and Sung, C. J., "Combustion and Ignition of Thermally Cracked Kerosene in Supersonic Model Combustors," Journal of Propulsion and Power, Vol. 23, No. 2, 2007, pp. 317-324. doi: $10.2514 / 1.26402$

[16] Fan, X., Yu, G., Li, J. G., Yue, L. J., Zhang, X. Y., and Sung, C. J., "Effects of Entry Conditions on Cracked Kerosene-Fueled Supersonic Combustor Performance," Combustion Science and Technology, Vol. 179, No. 10, 2007, pp. 2199-2217. doi:10.1080/00102200701386198

[17] Fan, X., Yu, G., Li, J. G., Lu, X. N., and Sung, C. J., "Catalytic Cracking of Supercritical Aviation Kerosene," 42th AIAA/ASME/SAE/ASEE Joint Propulsion Conference and Exhibit, AIAA Paper 2006-4868, Sacramento, CA, July 2006

[18] "NIST Thermophysical Properties of Hydrocarbon Mixtures Database: Version 3.2," NIST Standard Reference Database 4, National Inst. of Standards and Technology, Gaithersburg, MD, Feb. 1990.

C. Avedisian Associate Editor 